\title{
CRESCIMENTO E PRODUTIVIDADE DE DUAS CULTIVARES DE MILHO DE ALTA QUALIDADE PROTÉICA EM SOLO DE BAIXA FERTILIDADE(1)
}

\author{
ALANA DAS CHAGAS FERREIRA AGUIAR ${ }^{(2)}$; EMANOEL GOMES DE MOURA ${ }^{(2)}$
}

\begin{abstract}
RESUMO
As cultivares de milho com proteína de alto valor biológico (QPM), lançadas pela EMBRAPA, podem-se constituir em boa alternativa para a agricultura familiar brasileira. No trópico úmido seu desempenho dever ser confirmado nas condições prevalentes entre os agricultores. Diante disso, foi instalado, em janeiro de 1999, em Argissolo Vermelho-Amarelo Distrófico arênico e sob sistema de cultivo em aléias, um experimento em blocos ao acaso, com parcelas de $4 \times 6 \mathrm{~m}^{2}$ e quatro repetições, para avaliar o crescimento e a produtividade de duas cultivares de milho de alto valor protéico (BR 473 e BR 2121), em comparação com outras três utilizadas na agricultura maranhense: Ferro (cultivar tradicional, recolhida junto aos agricultores), BR 106 e AG 1051 (de baixo e médio nível tecnológico respectivamente). Foram avaliados o índice de área foliar, a taxa de assimilação líquida, o número de espigas, grãos por espiga, massa da espiga e de 100 grãos e o índice de colheita. Concluiu-se que a cultivar BR 473 pode ser recomendada para condições de solos ácidos de baixa fertilidade e para temperaturas altas, exceto BR 2121. A cultivar AG 1051 apresentou produtividade muito superior em relação às demais cultivares. $O$ uso generalizado da cultivar Ferro pela agricultura familiar só se justifica pela possibilidade de armazenamento na lavoura, que consiste em deixar o milho no campo, vários meses após a maturação, pela sua alta resistência às pragas de pós-colheita; ademais sua produtividade foi menor que todas as outras cultivares testadas.
\end{abstract}

Palavras-chave: milho QPM, crescimento, produtividade, alley cropping.

\section{ABSTRACT \\ GROWTH AND PRODUCTIVITY OF TWO HIGH QUALITY PROTEIN MAIZE CULTIVARS IN LOW FERTILITY SOIL}

Maize cultivars with protein of high biological value (QPM) developed by EMBRAPA would be a good alternative for the Brazilian low income farmers, but in the humid tropic their performances should be confirmed under local prevalent field conditions. A field experiment was done in January, 1999, in an Argisol and under the system of alley cropping, with plots of $4 \times 6 \mathrm{~m}^{2}$ and four replications, to evaluate the growth and productivity of two high quality protein maize cultivars (BR 473 and BR 2121) in comparison to three other related cultivars used in the farming system of Maranhao state: Ferro (traditional cultivar, collected with local farmers), BR 106 and AG 1051 (low and medium technological level

$\left({ }^{1}\right)$ Trabalho de monografia, Curso de Agronomia, da primeira autora, apresentada à Universidade Estadual do Maranhão, São Luís (MA). Recebido para publicação em 16 de setembro de 2002 e aceito em 24 de setembro de 2003.

$\left(^{2}\right)$ Laboratório de Solos, Caixa Postal 3004, 65054-970 São Luís (MA). E-mail: alanaaguiar@elo.com.br 
respectively). The leaf rate index, net assimilation rate, the number of cob, grain yield per cob, cob and 100 grains weight, and harvest index were evaluated. The results showed that cultivar BR 473 can be recommended to be cultivated in chemically stressed soil and high temperature conditions. The cultivar AG 1051 presented higher grain yield. The general use of local traditional cultivar Ferro by low income farmers can only be justified by the possibility of field storage, since its productivity was less than all other cultivars tested.

Key words: maize QPM, growth, productivity, alley cropping.

\section{Introdução}

Fisiologicamente, a adaptação de uma cultivar de milho a um certo local é determinada por fatores como resposta do crescimento da planta à temperatura, o desenvolvimento dos drenos (receptores) e a partição de fotossintetizados. LAFITTE et al. (1997) afirmam que a temperatura ótima para muitos processos fisiológicos no milho, como respiração e translocação de carboidratos, obedecem a uma faixa em que seu desempenho, na determinação do número de grãos por planta, não é afetado. Em áreas tropicais, esse é o principal parâmetro responsável pelas maiores oscilações de produtividade da cultura. A obtenção do maior número de grãos possível é uma função da população e do número de espigas por área.

Na cultura do milho, um cereal com sistema $\mathrm{C} 4$, com baixo ponto de compensação de $\mathrm{CO}_{2}$, o tamanho da espiga pouco contribui para a definição da produção, quando há pequeno número de espigas por unidade de área. Portanto, segundo FANCELLI (1999), pode-se inferir que o número de espigas é mais importante que o seu tamanho, para a produtividade da cultura. O número final de grãos por planta aumenta até um valor máximo à temperatura média de $22{ }^{\circ} \mathrm{C}$ durante o período de iniciação floral, e também aumenta linearmente com a radiação acumulada durante este período: 1,2 grão adicional é produzido para cada $100 \mathrm{cal}^{-2} \mathrm{~m}^{-2}$ acumulada. Fischer e PALMER (1984) constatam que, para um grande número de populações tropicais, o tamanho máximo do grão foi alcançado na temperatura média de $24,8^{\circ} \mathrm{C}$, com taxa de crescimento do grão de $6,84 \mathrm{mg}^{\text {dia }}{ }^{-1}$ e uma duração do enchimento efetivo do grão de 31 dias.

Dados de Magnavaca e Mertz (1992) mostraram que as variedades com proteína de boa qualidade QPM são $50 \%$ mais ricas em lisina e triptofano que os milhos comuns e, segundo Регхото et al. (1990), torna $1 \mathrm{~g}$ de proteína de qualidade QPM equivalente a $1,5 \mathrm{~g}$ da proteína do milho comum. Esses dados, já confirmados no Peru na alimentação infantil, comprovam que a recomendação destas cultivares nas condições do trópico úmido, pode ser altamente desejável, mas não deve prescindir das informações a respeito de seu comportamento nas condições de solo e clima predominantes na agricultura da região. $\mathrm{O}$ objetivo deste trabalho foi avaliar o crescimento e a produtividade de duas cultivares de milho QPM, em comparação com outras três cultivares pertencentes aos três grupos utilizados na agricultura do Maranhão: tradicional, de menor e de médio nível tecnológico.

\section{Material e Métodos}

O experimento foi desenvolvido no campo experimental do Núcleo Tecnológico de Engenharia Rural do Curso de Agronomia da Universidade Estadual do Maranhão, Latitude S $2^{\circ} 36^{\prime}$ e Longitude W $44^{\circ} 13^{\prime}$, com temperaturas máximas de 34 a $42^{\circ} \mathrm{C}$ e mínimas de 23 a $26^{\circ} \mathrm{C}$ e precipitação pluvial variando de 1.900 a $2.300 \mathrm{~mm}$ por ano. O solo da área do experimento foi, segundo o Sistema Brasileiro de Classificação de Solos (EMBRAPA, 1999), denominado Argissolo Vermelho-Amarelo Distrófico arênico. Os dados de temperatura e precipitação pluvial foram obtidos na Estação Meteorológica do Núcleo Tecnológico de Engenharia Rural.

Utilizou-se o feijão guandu (Cajanus cajan) como espécie arbustiva, em sistema de cultivo em aléias, no espaçamento de $2 \times 0,5 \mathrm{~m}$ e fileiras de $6 \mathrm{~m}$ de comprimento, delineadas em blocos ao acaso, com quatro repetições. As cultivares de milho usadas foram: Ferro (variedade tradicional utilizada na agricultura familiar do Maranhão); BR 106 (variedade melhorada recomendada para menor nível tecnológico); BR 473 (variedade QPM); BR 2121 (híbrido QPM); AG 1051 (híbrido duplo indicado para médio nível tecnológico).

$\mathrm{Na}$ adubação utilizou-se 20-60-40 kg.ha-1 de nitrogênio, $\mathrm{P}_{2} \mathrm{O}_{5}$ e $\mathrm{K}_{2} \mathrm{O}$, respectivamente, na forma de uréia, superfosfato simples e cloreto de potássio. $\mathrm{O}$ plantio foi realizado na primeira semana de janeiro de 1999, com densidade de cinco plantas por metro. O corte e a cobertura do solo com os ramos da leguminosa foram feitos uma semana após, para evitar sombreamento às plantas de milho. Para adubação em cobertura, aplicou-se $40 \mathrm{~kg}$.ha ${ }^{-1}$ de nitrogênio, na forma de uréia, aos 30 dias após a emergência das plantas. 
Avaliou-se a variação da área foliar (AF) e da matéria seca (MS) com a idade da planta. Para tanto, foram coletadas, em intervalos de sete dias, a partir do $16 .^{\circ}$ dia após a emergência, quatro plantas por parcela, escolhidas nas linhas das bordas, deixando as centrais para a análise de produção, totalizando seis coletas. A área foliar foi obtida por meio do integrador de área foliar da LICOR, modelo 3100.

Utilizando a variação da área foliar e matéria seca, calcularam-se os parâmetros fisiológicos da análise de crescimento: índice de área foliar (IAF) e taxa de assimilação líquida (TAL). A taxa de assimilação líquida fornece a influência das folhas na produção de novos materiais e pode ser definida pelas expressões $\mathrm{TAL}=\mathrm{dMS} / \mathrm{dt} / \mathrm{IAF}$. Neste trabalho, o índice foi estimado por meio do programa ANACRES, segundo Portes e Castro Júnior (1991).

As alturas de planta e de inserção das espigas foram medidas utilizando uma amostra de dez plantas por parcela e, para a classificação das cultivares de milho quanto ao ciclo empregou-se a equação [( Temperatura máxima + Temperatura mínima) / 2] - 10, adotando-se os limites de 830 e 875 unidades de calor, para a classificação em superprecoce, precoce e normal.

O Índice de Colheita, determinado pela razão entre a produção econômica e a produção biológica da planta, no presente trabalho foi fixado a partir de dez plantas secas em estufas com circulação forçada a 70 ${ }^{\circ} \mathrm{C}$. Os grãos obtidos foram pesados separadamente e a massa encontrada foi dividida pela massa total das plantas, incluindo os grãos. Para a análise de produção foram avaliados: número de espigas, grãos por espiga, massa da espiga e de 100 grãos. Os resultados foram submetidos à análise de variância, utilizando o teste $\mathrm{F}$ ao nível de $5 \%$. A comparação das médias foi feita com o teste de Tukey, a $5 \%$. Os dados da TAL foram submetidos à análise de regressão.

\section{Resultados e Discussão}

Os resultados da análise de solo do local do experimento, indicados no quadro 1 , mostraram que o pH e a saturação por bases (V\%) estavam bem abaixo dos recomendados por RAIJ et al. (1997) para a cultura do milho, o que significa possibilidade de seleção para tolerância a estresse na zona das raízes, principalmente quanto à adaptabilidade à acidez excessiva e à baixa disponibilidade de cálcio, magnésio e potássio. Os níveis de fósforo também não asseguravam expectativa de alta produtividade, segundo os mesmos autores.

A ocorrência de uma precipitação pluvial de $1.360 \mathrm{~mm}$ bem distribuídos durante o ciclo da cultura mostra que não houve déficit hídrico no solo e, como se espera para a região Centro-Norte do Maranhão, é maior a possibilidade de excesso que falta de água no solo durante o período de cultivo do milho.

A temperatura do ar oscilou entre 24 e $36{ }^{\circ} \mathrm{C}$ durante o experimento, com ligeira elevação das temperaturas máximas a partir do período de iniciação floral, ultrapassando os limites críticos para obter o maior número de grãos, segundo Fischer e PALMER (1984), sugerindo condições efetivas para comparar a adaptabilidade dos milhos testados no experimento, quanto à tolerância a temperaturas elevadas.

No que se refere ao porte das plantas, verificou-se que apenas as cultivares "Ferro" e BR 106 apresentaram alturas de plantas e espigas acima do aceitável, quando se busca melhor partição de fotoassimilados e diminuição do tombamento das plantas antes da colheita (Quadro 2). A cultivar tradicional apresentou altura de inserção da espiga quase duas vezes superior à de BR 473, o que pode acarretar tombamento de plantas após a maturação.

As duas cultivares QPM e o híbrido AG 1051, de acordo com as unidades de calor exigidas, se mostraram superprecoces, contrastando com a cultivar preferida pelos produtores, Ferro, que apresentou ciclo muito mais longo (Quadro 3). Essa diferença deve ser levada em conta, quando da recomendação de cultivares, uma vez que em boa parte da região do trópico úmido, o período chuvoso ultrapassa 180 dias. Esse excesso de umidade pode dificultar a secagem das espigas no campo, e levar à germinação das sementes nas espigas, que amadurecem precocemente, como observado por Fischer e PALmer (1984) e constatado pelos autores em visita aos agricultores.

Quadro 1. Resultados da análise química do solo do experimento

\begin{tabular}{|c|c|c|c|c|c|c|c|c|c|c|}
\hline Profundidade & $\mathrm{P}$ & $\mathrm{pH}$ & $\mathrm{K}$ & $\mathrm{Ca}$ & $\mathrm{Mg}$ & $\mathrm{H}+\mathrm{Al}$ & $S$ & $\mathrm{~T}$ & $\mathrm{~V}$ & M.O. \\
\hline $\mathrm{cm}$ & $\mathrm{mg} \cdot \mathrm{dm}^{-3}$ & $\mathrm{CaCl}_{2}$ & \multicolumn{6}{|c|}{$\mathrm{mmol}^{\mathrm{c}} \cdot \mathrm{dm}^{-3}$} & $\%$ & g.dm ${ }^{-3}$ \\
\hline $0-20$ & 1,0 & 3,9 & 0,7 & 7 & 8 & 26 & 15 & 41 & 36 & 8,0 \\
\hline $20-40$ & 1,0 & 3,7 & 0,6 & 5 & 5 & 26 & 10 & 36 & 28 & 5,0 \\
\hline
\end{tabular}


Quadro 2. Alturas médias das plantas, da inserção das espigas e valor relativo (VR) apresentados pelas cultivares de milho

\begin{tabular}{lcccc}
\hline \multirow{2}{*}{ Cultivares } & \multicolumn{3}{c}{ Altura média } \\
\cline { 2 - 5 } & Planta & $\mathrm{VR}^{(1)}$ & Espiga & $\mathrm{VR}^{(1)}$ \\
\hline FERRO & $\mathrm{m}$ & $\%$ & $\mathrm{~m}$ & $\%$ \\
BR 106 & $3,07 \mathrm{a}^{(2)}$ & 135 & $1,85 \mathrm{a}$ & 193 \\
AG 1051 & $2,84 \mathrm{ab}$ & 125 & $1,47 \mathrm{~b}$ & 153 \\
BR 2121 & $2,41 \mathrm{c}$ & 106 & $1,10 \mathrm{c}$ & 114 \\
BR 473 & $2,34 \mathrm{c}$ & 103 & $0,98 \mathrm{c}$ & 102 \\
\hline
\end{tabular}

$\left({ }^{1}\right) \mathrm{O}$ valor relativo tem como base a cultivar BR 473 .

Médias seguidas das mesmas letras, na coluna, não diferem entre si pelo teste de Tukey ao nível de 5\%.

Quadro 3. Classificação das cultivares de milho, com base nas unidades de calor necessárias para o florescimento da metade das plantas

\begin{tabular}{lcr}
\hline Cultivares & Unidades de calor ${ }^{(1)}$ & Ciclo \\
\hline FERRO & 950,7 & Normal \\
BR 106 & 832,2 & Precoce \\
BR 473 & 781,0 & Superprecoce \\
AG 1051 & 731,4 & Superprecoce \\
BR 2121 & 681,2 & Superprecoce \\
\hline
\end{tabular}

$\left({ }^{1}\right)$ Soma térmica - superprecoce (abaixo de 830), precoce (de 830 a 875), normal (acima de 875 ).

O Índice de área foliar foi significativamente diferente entre cultivares. Aos 51 dias após a emergência a variedade tradicional apresentava IAF 100\% superior à BR 473 e 70\% superior ao híbrido BR 2121, o que mostra maior adaptabilidade traduzida em maior potencial de produção biológica da cultivar tradicional em relação às QPMs (Figura 1).

Os resultados de TAL por área foliar, apresentados na figura 2, foram ajustados por meio de uma função polinomial. Os dados sugerem maior eficiência na produção de fotossintetizados por área de folha da variedade BR 473 (QPM), principalmente em relação ao BR 2121 e à BR 106, o que lhe possibilitaria compensar a menor área de folha. O híbrido BR 2121 combinou a menor eficiência fotossintética com uma pequena superfície foliar, sugerindo baixa adaptabilidade às condições deste experimento.

As diferenças na produção de matéria seca foram significativas e se acentuaram na fase reprodutiva, principalmente entre a cultivar AG 1051 e o híbrido BR 2121, o que pode ser explicado pelo fato de a primeira apresentar maior área foliar com grande produtividade por área da folha, mesmo com os níveis de disponibilidade de nutrientes aquém dos recomendados para uma cultivar de médio nível tecnológico. A alta produtividade biológica alcançada por esse híbrido melhorado no Brasil, comparada com dados obtidos nos EUA (HAY, 1995), revela que os melhoristas brasileiros optaram pelo aumento na produção de matéria seca paralelamente ao incremento do índice de colheita, visando ao aumento da produção econômica. Entre os QPMs, o híbrido BR 2121 se mostrou intolerante às condições do experimento e a variedade BR 473, embora com menor área de folha, alcançou boa produtividade biológica, o que pode ser devido à maior eficiência de sua superfície fotossintética (Figura 3).

Com relação à partição de assimilados, os híbridos apresentaram maior habilidade a fim de destinar o resultado da fotossíntese para a produção de grãos, o que também ocorreu para a cultivar AG 1051. O pior índice foi o da 'FERRO', que destinou mais de $70 \%$ do material produzido para colmos e palha. O índice de colheita alcançado pela variedade BR 473 foi considerado alto para uma variedade, principalmente se comparada com a também variedade BR 106, embora os índices de colheita dessas duas cultivares não diferiram estatisticamente (Quadro 4). 


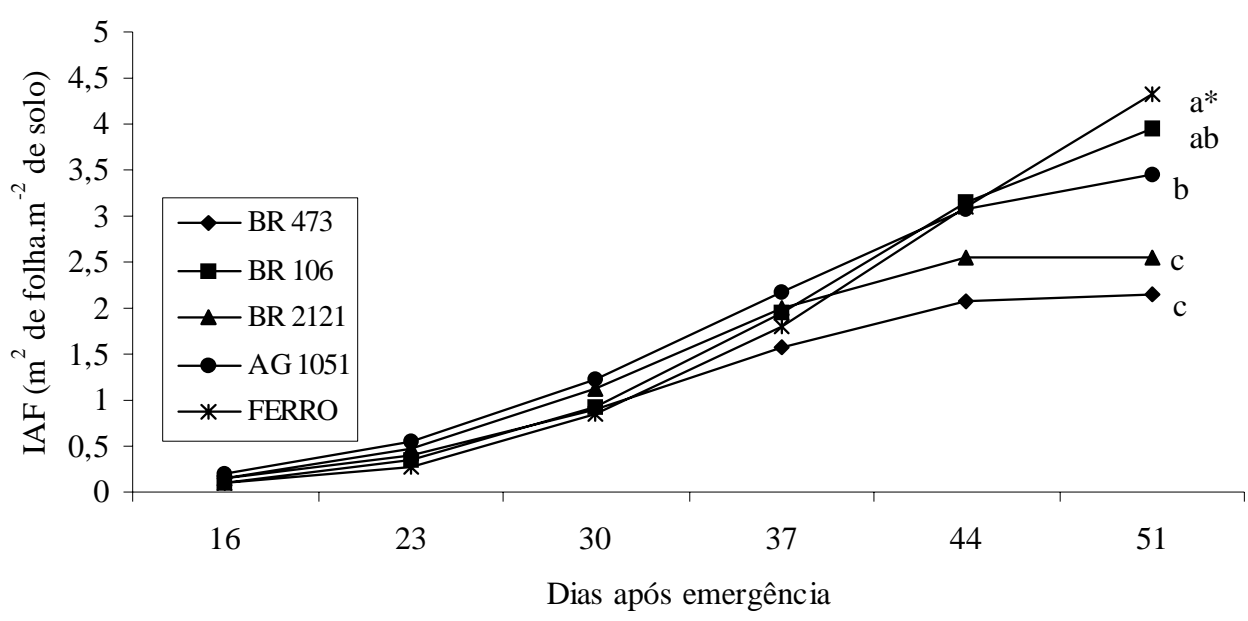

Figura 1. Índice de área foliar das cultivares de milho a partir dos 16 dias de emergência. * Pontos seguidos das mesmas letras não diferem entre si pelo teste de Tukey ao nível de 5\%.

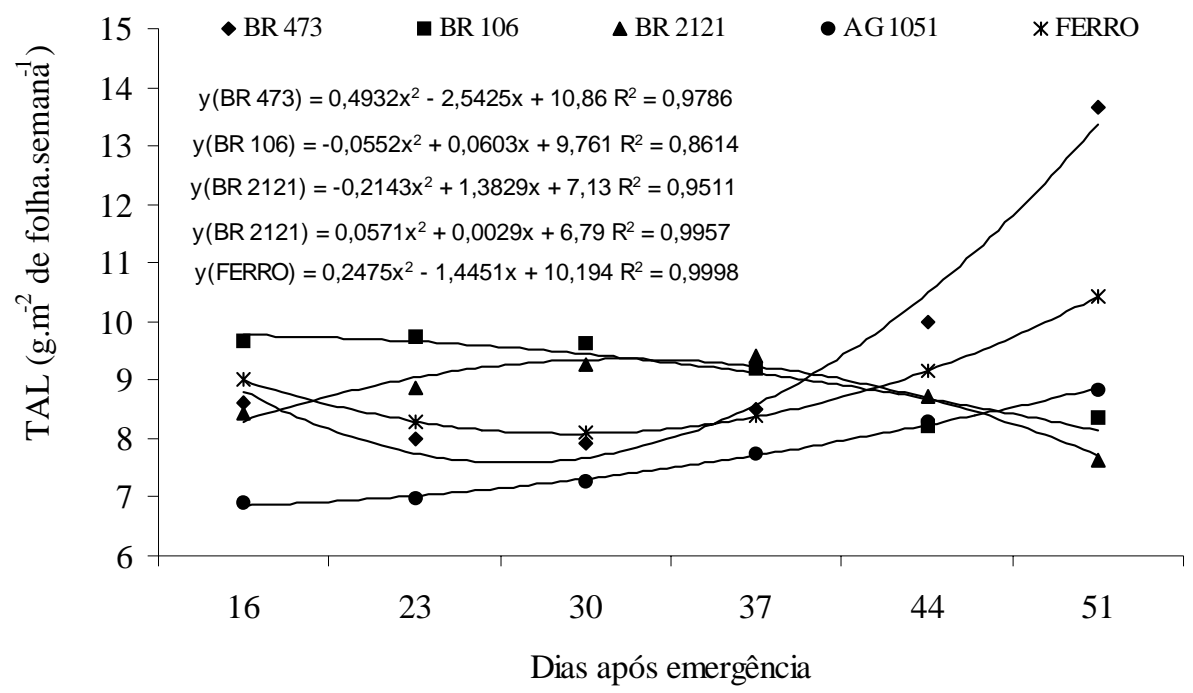

Figura 2. Taxa de assimilação líquida das cultivares de milho a partir dos 16 dias de emergência.

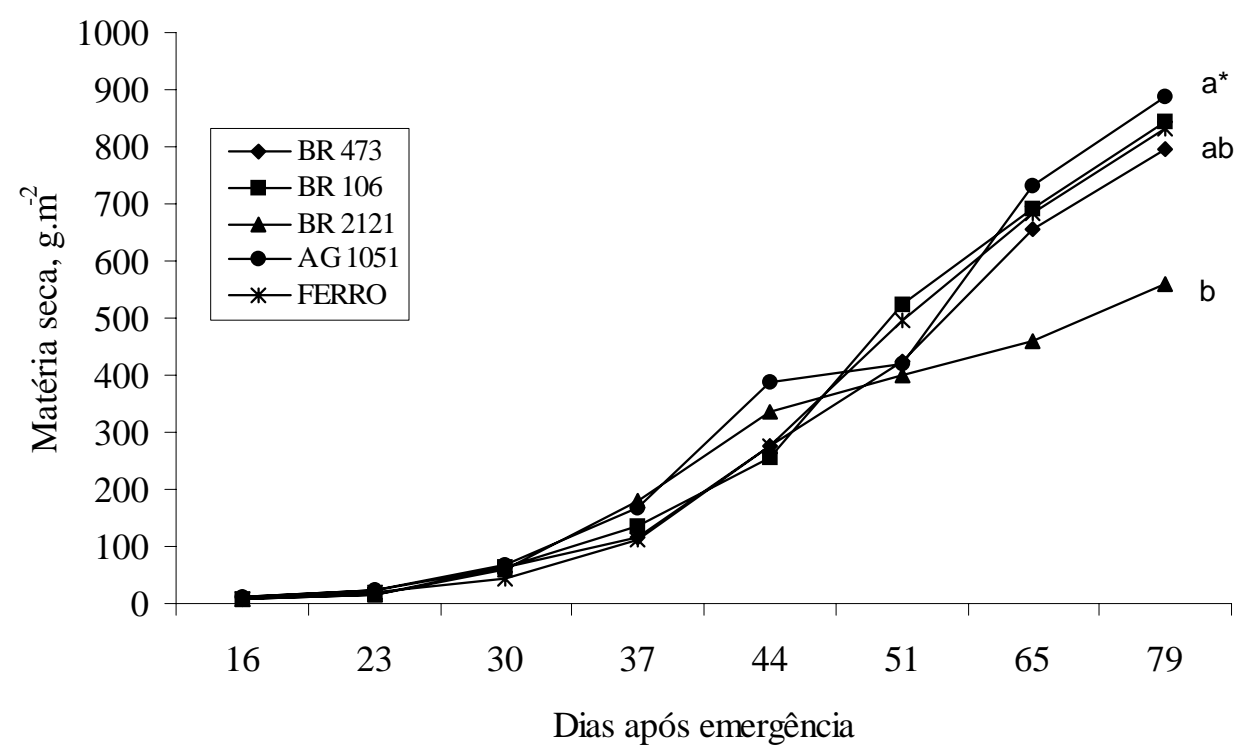

Figura 3. Matéria seca acumulada pelas cultivares de milho a partir dos 16 dias de emergência. ${ }^{*}$ Pontos seguidos das mesmas letras não diferem entre si pelo teste de Tukey ao nível de 5\%. 
Quadro 4. Parâmetros da produção das cultivares de milho

\begin{tabular}{|c|c|c|c|c|c|c|}
\hline \multirow{2}{*}{ Parâmetros de produção } & \multicolumn{5}{|c|}{ Cultivares } & \multirow[b]{2}{*}{$\mathrm{CV}$} \\
\hline & AG 1051 & BR 473 & BR 106 & BR 2121 & FERRO & \\
\hline & & & & & & $\%$ \\
\hline Espigas por $\mathrm{m}^{2}$ & $5 \mathrm{~A}$ & $5 \mathrm{~A}$ & $4 \mathrm{~A}$ & $4 \mathrm{~A}$ & $4 \mathrm{~A}$ & 6,48 \\
\hline Grãos por espiga & $332 \mathrm{~A}$ & $341 \mathrm{~A}$ & $307 \mathrm{~A}$ & $309 \mathrm{~A}$ & $321 \mathrm{~A}$ & 12,65 \\
\hline Massa da espiga (g) & $84,2 \mathrm{~A}$ & $69,3 \mathrm{AB}$ & $70,9 \mathrm{AB}$ & $57,0 \mathrm{~B}$ & $53,4 \mathrm{~B}$ & 12,45 \\
\hline Massa de 100 grãos (g) & 25,3 & 20,3 & 23,1 & 18,4 & 16,6 & \\
\hline Produção de matéria seca $\left(\mathrm{kg} \cdot \mathrm{ha}^{-1}\right)$ & 8877 A & $7950 \mathrm{AB}$ & 8429 AB & 5598 B & 8304 AB & 16,53 \\
\hline Índice de colheita (\%) & $44 \mathrm{~A}$ & $40 \mathrm{AB}$ & $34 \mathrm{BC}$ & $43 \mathrm{AB}$ & $27 \mathrm{C}$ & 10,82 \\
\hline Produção de grãos (kg.ha-1) & $4210 \mathrm{~A}$ & $3465 \mathrm{AB}$ & 2836 B & $2280 \mathrm{~B}$ & 2136 B & 14,64 \\
\hline
\end{tabular}

*Médias seguidas das mesmas letras, na linha, não diferem entre si pelo teste de Tukey ao nível de 5\%.

A análise dos parâmetros de produção econômica permite verificar que as variedades mais produtivas se destacaram graças à maior massa das espigas e dos grãos, o que concorda com os dados de HAY (1995) sobre os híbridos norte-americanos. Quanto à produção econômica, destacou-se positivamente a variedade BR 473, confirmando a perspectiva de sua utilização para a agricultura familiar.

As cultivares BR 2121 e Ferro se mostraram pouco produtivas: a primeira por inadaptabilidade às condições do experimento, expressa pela baixa produção biológica e a segunda, em função do baixo índice de colheita, resultado de sua característica de cultivar não melhorada. A produtividade da BR 106, variedade rústica, não correspondeu à expectativa gerada, pelo fato de se constituir no milho mais semeado no Brasil, desde que neste experimento apresentou performance abaixo da variedade QPM.

\section{Conclusões}

1. A cultivar QPM BR 473 pode ser recomendada para condições tropicais e de solo ácido de baixa fertilidade. Nas regiões de período chuvoso muito extenso, porém, deve ser considerada a possibilidade de deterioração dos grãos no campo, devido a sua superprecocidade.

2. O híbrido BR 2121 não deve ser recomendado para condições de baixa fertilidade do solo, desde que apresente menor tolerância ao estresse químico do que a variedade BR 473 , com a desvantagem adicional de obrigatoriedade da compra anual de sementes.
3. Para produção de milho sem qualidade alimentar diferenciada, a cultivar AG 1051 deve ter preferência em relação às variedades BR 106 e Ferro, por apresentar produtividade de grãos muito superior, mesmo em condições de fertilidade do solo abaixo das recomendadas para cultivares de médio nível tecnológico.

4. O uso generalizado da variedade tradicional Ferro, na agricultura familiar do Maranhão, somente se justifica pela possibilidade de armazenamento no campo, em razão da extrema resistência de seus grãos a ataque de pragas e apodrecimento após a maturação. No entanto, sua baixa produtividade e a potencialidade da BR 473 mostrada neste experimento justificam a busca de melhorias nas condições de armazenamento dos grãos na propriedade.

\section{Referências Bibliográficas}

EMBRAPA. Centro Nacional de Pesquisa de Solos (Rio de Janeiro, RJ). Sistema brasileiro de classificação de solos. Brasília: Embrapa Produção de Informação; Rio de Janeiro: Embrapa Solos, 1999, 412p.

FANCELLI, A.L. Fenologia do milho. [online] 1999. Disponível: http:/alta vista.com.br [acesso em 20 fev. 1999].

FISCHER, K.S.; PALMER, F.E. Tropical maize. In: GOLDSWORTHY, P.R.; FISCHER, N.M. (Eds.). The physiology of tropical field crops. New York: Wiley Interscience, 1984. p.213248.

HAY, R.K.M. Harvest index: a review of its use in plant breeding and crop physiology. Annals of Applied Biology, Wellesbourne, v.126, p.197-216, 1995. 
LAFITTE, H.R.; EDMEADES, G.O.; JOHNSON, E.C. Temperature responses of tropical maize cultivars selected for broad adaptation. Field Crops Research, Amsterdam, v.49, p.215-229, 1997.

MADDONNI, G.A.; OTEGUI, M.E.; BONHOMME, R. Grain yield components in maize: II. Postsilking growth and kernel weight. Field Crops Research, Amsterdam, v.56, p.257-264, 1998.

MAGNAVACA, R.; MERTZ, E. T. Quality protein maize development in Brazil. CAB Abstracts, London, p.98-110, 1992.

PEIXOTO, M.J.V.V.; MAGNAVACA, R.; PARENTONI, S.N.; GAMA, E.G.; REGO, M.M. do. Perspectiva de utilização de milhos de alta qualidade protéica no Brasil. Informe Agropecuário, Belo Horizonte, v.14, n.165, p. 23-34, 1990.
PORTES, T.A.; CASTRO JÚNIOR, L.G. Análise de crescimento de plantas: um programa computacional auxiliar. Revista Brasileira de Fisiologia Vegetal, Brasília, v. 3, n. 1, p. 53-56, 1991.

RAIJ, B. van; CANTARELLA, H.; QUAGGIO, J.A.; FURLANI, A.M.C. Recomendações de adubação e calagem para o Estado de São Paulo. Campinas: Instituto Agronômico, 1997. 285p. (Boletim Técnico, 100) 